\title{
RHD-Positive Alleles among D- C/E+ Individuals from India
}

\author{
Swati S. Kulkarni ${ }^{a}$ Harita Gogria Disha Parchure ${ }^{a}$ Garima Mishra $^{a}$ Kanjaksha Ghosh ${ }^{a}$ \\ Sunil Rajadhyaksha ${ }^{b}$ Manisha Madkaikar ${ }^{a}$ Claude Férec $^{c, d}$, e, f Yann Fichou ${ }^{c, d}$ \\ ${ }^{a}$ National Institute of Immunohematology, Indian Council of Medical Research (NIIH-ICMR), Mumbai, India; \\ ${ }^{b}$ Department of Transfusion Medicine, Tata Memorial Hospital, Mumbai, India; \\ ' Institut National de la Santé et de la Recherche Médicale (Inserm), UMR1078, Brest, France; \\ ${ }^{d}$ Etablissement français du sang Bretagne, Brest, France; \\ e Laboratoire de Génétique Moléculaire et d'Histocompatibilité, Centre Hospitalier Régional Universitaire (CHRU), Hôpital Morvan, Brest, \\ France; \\ ${ }^{f}$ Faculté de Médecine et des Sciences de la Santé, Université de Bretagne Occidentale (UBO), Brest, France
}

\section{Keywords}

Allele · D-negative $\cdot$ Molecular basis · Phenotype $\cdot$ RHD

\section{Summary}

Background: Molecular bases of blood group systems, including Rh blood group, have been poorly studied in the Indian population so far, while specificities of Europeans, East Asians and Africans have been well known for years. In order to gain insights into the molecular bases of this population, we sought to characterize the $R H D$ allele in D- Indian donors expressing $C$ and/or $\mathrm{E}$ antigen(s). Methods: RHD gene was analyzed in 171 serologically $\mathrm{D}-, \mathrm{C} / \mathrm{E}+$ samples by standard molecular methods such as quantitative, multiplex PCR of short fluorescent fragments (QMPSF) and direct sequencing when necessary. Results: $R H D$ whole gene deletion at the homozygous state was found to be the most common genotype associated with D- phenotype (118/171, $69.0 \%$ ). Nonfunctional, negative hybrid genes with reported molecular backgrounds were observed in approximately one-third of the samples, while only four samples carry single-nucleotide variations, including one novel nonsense $(\operatorname{RHD}(\mathrm{Y} 243 \mathrm{X}))$, one novel frameshift $(R H D$ (c.701delG)), and two missense ( $R H D(T 148 \mathrm{R})$ and RHD(T148R, T195M)) alleles. Conclusion: Overall we report for the first time the molecular bases of $D$ antigen negativity in the $\mathrm{D}-, \mathrm{C} / \mathrm{E}+$ Indian population, which appears to be qualitatively similar to other populations, but with a population-specific, quantitative distribution of $D$ alleles.

(C) 2018 S. Karger GmbH, Freiburg

\section{Introduction}

$\mathrm{D}$ antigen in the $\mathrm{Rh}$ blood group system is of critical importance due to its involvement in hemolytic disease of the fetus and newborns and in hemolytic transfusion reactions [1]. Anti-D immunization may occur in D- recipients. Frequency of D- varies widely with ethnic-specific distribution: typically $11-17 \%$ in Caucasians, $3-7 \%$ in Africans, and $<1 \%$ in East Asians [2-5]. The most frequent cause of D- phenotype in Caucasians is the absence of functional $\mathrm{RhD}$ protein, which results from the whole deletion of the RHD gene $[3,5]$. In D- Black Africans, $66 \%$ and $15 \%$ carry the nonfunctional RHD pseudogene (RHD $)$ ) and RHD-CE- $D^{s}$ hybrid alleles, respectively, while $18 \%$ lacked the RHD gene [6]. Although the main $R H D$ alleles resulting in a D-phenotype, i.e. $R H D \Psi$ and $(C) c e^{s}$, are most frequently cis-associated with $R H C E^{*} c e$, other $R H D$ gene variants in $\mathrm{D}$ - individuals, including several hybrid genes, have been shown to segregate with RHCE alleles expressing $\mathrm{C}$ and/or $\mathrm{E}(\mathrm{C} / \mathrm{E}+)$ antigens in Caucasian, Asian, African, and mixed populations [4, 7-20].

Several studies have reported that $3-7 \%$ of Indians harbor a Dphenotype [21-23]. Expression of C and/or E antigen(s) has already been observed in this subset of population (personal unpublished data). As opposed to the aforementioned populations, the underlying mechanism responsible for $\mathrm{RhD}$ negativity has not been elucidated in the Indian population. Hence we then sought to systemically analyze and characterize the RHD locus in D-, C/E+ Indian blood donors by using standard molecular approaches in an effort to gain insights into the specific molecular basis of $\mathrm{D}$ antigen negativity in this population.

\section{KARGER}

() 2018 S. Karger GmbH, Freiburg

Fax +497614520714 
Fig. 1. Genotyping $\mathrm{D}-, \mathrm{C} / \mathrm{E}+$ samples by RHD QMPSF analysis. Typical profiles obtained in samples with A wild-type $R H D$ (hemizygous calibrator sample, Ccee);

B homozygous RHD deletion (ccEe);

C homozygous $R H D$ deletion (Ccee); D hemizygous RHD$C E(3-8)-D$ (Ccee);

E hemizygous $R H D$ $C E$ (4-9)-D (Ccee); and F hemizygous $R H D$ $C E$ (3-9)-D (Ccee). ${ }^{*}$ Absence of the respective exon markers; HFE and F9: positive control gene markers; e1 to e10: RHD exons 1 to 10 ; $\mathrm{x}$-axis: base pairs; $\mathrm{y}$-axis: relative fluorescence intensity.

C

D

$\mathbf{F}$
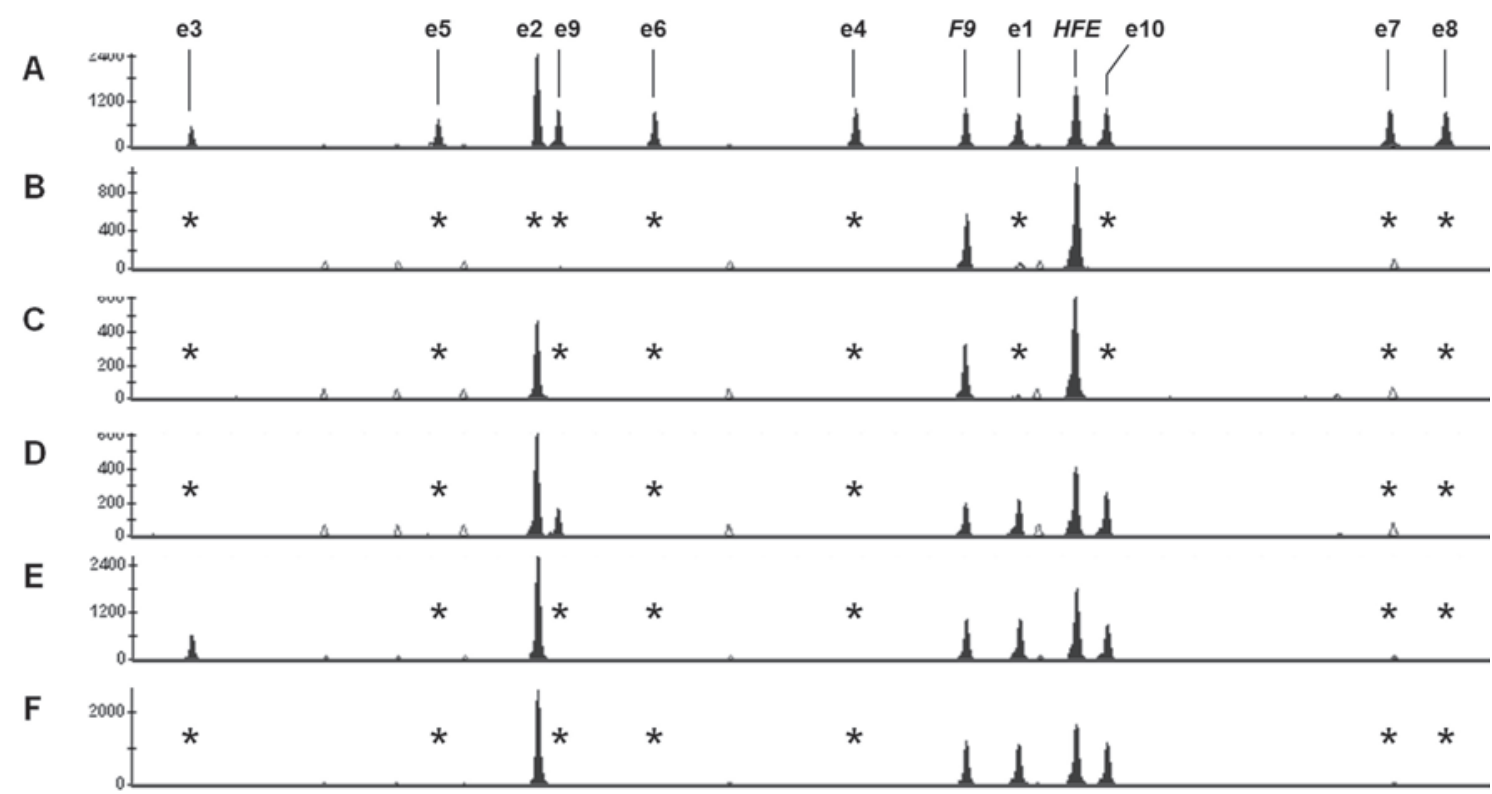

Table 1. $R H D$ genotype in $171 \mathrm{D}-, \mathrm{C} / \mathrm{E}+$ Indian blood donors

\begin{tabular}{|c|c|c|c|c|}
\hline \multirow[t]{2}{*}{ Genotype } & \multicolumn{3}{|c|}{ Occurrence (\%) } & \multirow[t]{2}{*}{ Total (\%) } \\
\hline & Ccee & CCee & $\mathrm{ccEe}$ & \\
\hline$R H D^{*} 01 N .01 / R H D^{*} 01 N .01$ & $99(57.9 \%)$ & - & $19(11.1 \%)$ & $118(69.0 \%)$ \\
\hline RHD ${ }^{*} 01 N .01 / R H D-C E(3-9)-D$ & $28(16.4 \%)$ & - & - & $28(16.4 \%)$ \\
\hline$R H D^{*} 01 N .01 / R H D-C E(3-8)-D$ & $15(8.8 \%)$ & - & - & $15(8.8 \%)$ \\
\hline RHD*01N.01 / RHD-CE(4-9)-D & $5(2.9 \%)$ & - & $1(0.6 \%)$ & $6(3.5 \%)$ \\
\hline$R H D^{*} 01 N .01 / R H D(T 148 R)$ & $1(0.6 \%)$ & - & - & $1(0.6 \%)$ \\
\hline RHD*01N.01 / RHD(T148R, T195M) ${ }^{a}$ & - & $1(0.6 \%)$ & - & $1(0.6 \%)$ \\
\hline$R H D^{*} 01 N .01 / R H D(Y 243 X)^{a}$ & $1(0.6 \%)$ & - & - & $1(0.6 \%)$ \\
\hline RHD-CE(3-9)-D / RHD(c.701delG) $)^{a}$ & $1(0.6 \%)$ & - & - & $1(0.6 \%)$ \\
\hline Total & $150(87.7 \%)$ & $1(0.6 \%)$ & $20(11.7 \%)$ & $171(100.0 \%)$ \\
\hline
\end{tabular}

$R H D^{*} 01 N .01$ refers to as the whole $R H D$ gene deletion, in accordance with the nomenclature recommended by the International Society of Blood Transfusion (ISBT Blood Group Terminology: www.isbtweb.org/fileadmin/user_upload/files-2015/red\%20cells/ blood\%20group\%20allele\%20terminology/allele\%20tables/004_RHD_Negative_Null_Alleles_v3_0.pdf). ${ }^{a}$ Novel allele.

\section{Material and Methods}

Samples and Serological Analysis

Blood samples from 171 individuals of Indian origin, typed as D- but C+ and/or E+ by routine serological analyses, were taken for the study. Serologic typing for $\mathrm{D}, \mathrm{C} / \mathrm{c}$, and $\mathrm{E} / \mathrm{e}$ antigens was performed using the commercial antiD, anti-C, anti-c, anti-E and anti-e antisera (MS24, MS33, MS260, MS16, MS21, MS63). All tests were performed in accordance with the manufacturer's instructions (Bio-Rad Laboratories, Diamed GmbH, Cressier, Switzerland) by tube technique. In addition, an indirect antiglobulin test and adsorption/elution tests [24] were performed for all samples to detect weak D and DEL phenotype.

\section{Molecular Typing}

DNA was isolated from $5 \mathrm{ml}$ of blood by phenol chloroform method. Al D-, C+ and/or E+ samples were first screened for the presence of all ten $R H D$ exons by quantitative multiplex PCR of short fluorescent fragments (i.e. RHD QMPSF) for exon copy number variation assessment in conditions previously described [25]. When hybrid genes were suspected, RHCE QMPSF was carried out [25]. Sanger sequencing was performed as previously described when QMPSF analysis was inconclusive [26].

\section{Results}

171 individuals typed as $\mathrm{D}-$ but $\mathrm{C}+$ and/or $\mathrm{E}+$ by serology (phenotype ddCcee: $\mathrm{n}=150$; ddCCee: 1 ; ddccEe: 20 ) were analyzed. Weak D and DEL phenotypes were not detected in these samples.

As both $R H D$ whole gene deletion and hybrid RHD-RHCE genes have been commonly reported, DNA samples were first screened for the presence of all ten RHD exons by QMPSF analysis, a quantitative method that has proven useful for assessment of 
Fig. 2. Molecular analysis of the $R H D$ locus in $\mathrm{D}-, \mathrm{C} / \mathrm{E}+$ samples. A Genotyping data of the compound heterozygous sample by $R H D$ QMPSF analysis (left, $R H D-C E(4-9)-D)$ and Sanger sequencing (right, RHD(c.701delG)). Sanger sequencing profiles in samples presenting with the novel B $R H D(\mathrm{~T} 148 \mathrm{R})$

C $R H D(\mathrm{Y} 243 \mathrm{X})$, and

D $R H D(\mathrm{~T} 148 \mathrm{R}$,

T195M) alleles.

${ }^{*}$ Copy number variation of RHD exon

markers (i.e. $\mathrm{n}=1$,
A

RHD QMPSF

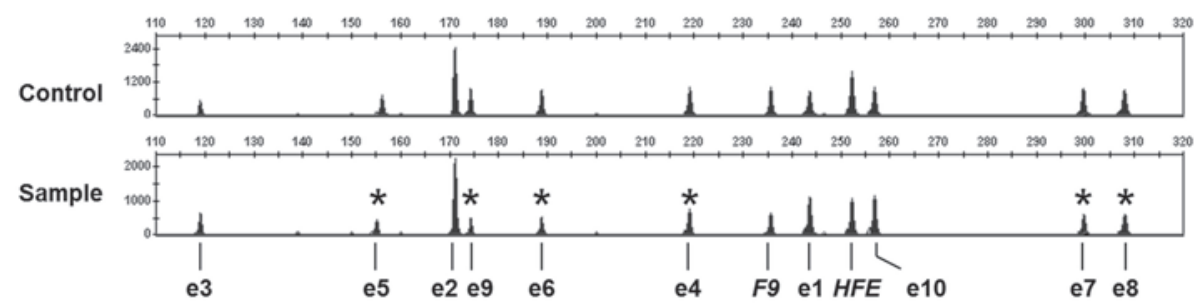

B

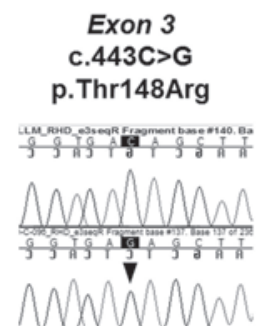

Exon 5

c.701delG p.Lys235ArgfsX11

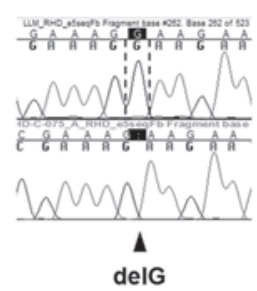

Exon 4

c. $584 \mathrm{C}>\mathrm{T}$ p.Thr195Met
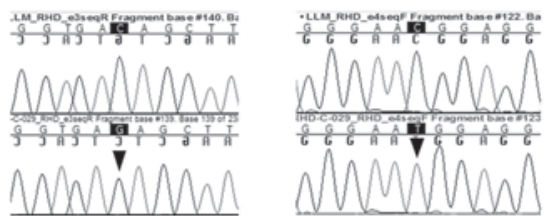

while two copies of the gene were calculated); HFE and F9: positive control gene markers; e1 to e10: exons 1 to 10; arrowhead: position of single nucleotide variation.

Table 2. Example of RHD genotype distribution in $\mathrm{D}-, \mathrm{C} / \mathrm{E}+$ individuals of various origins

\begin{tabular}{|c|c|c|c|c|c|c|}
\hline \multirow{3}{*}{$\begin{array}{l}\text { Population origin } \\
\text { Mixed (Brazil) }\end{array}$} & \multicolumn{4}{|c|}{ Genotype (occurrence, \%) } & \multirow{3}{*}{$\begin{array}{l}\text { Total } \\
520\end{array}$} & \multirow{3}{*}{$\begin{array}{l}\text { Reference } \\
17\end{array}$} \\
\hline & \multicolumn{2}{|c|}{ RHD deletion ${ }^{\mathrm{a}}$} & \multicolumn{2}{|c|}{ Hybrid gene + others $^{\mathrm{b}}$} & & \\
\hline & 502 & $(96.5 \%)$ & 18 & $(3.5 \%)$ & & \\
\hline Caucasian (Denmark) & 225 & $(96.4 \%)$ & 8 & $(3.4 \%)$ & 233 & 14 \\
\hline Caucasian (Multicenter) & 1,611 & $(94.8 \%)$ & 89 & $(5.2 \%)$ & 1,700 & 9 \\
\hline Asian (Japan) & 2,216 & $(83.6 \%)$ & 334 & $(16.4 \%)$ & 2,650 & 20 \\
\hline Mixed (Argentina) & 95 & $(83.3 \%)$ & 19 & $(16.7 \%)$ & 114 & 19 \\
\hline African (Tunisia) & 75 & $(75.0 \%)$ & 25 & $(25.0 \%)$ & 100 & 18 \\
\hline Indian & 118 & $(69.0 \%)$ & 53 & $(31.0 \%)$ & 171 & this study \\
\hline Asian (Japan) & 65 & $(63.1 \%)$ & 38 & $(36.9 \%)$ & 103 & 4 \\
\hline Asian (China) & 21 & $(38.2 \%)$ & 34 & $(61.8 \%)$ & 55 & 12 \\
\hline Asian (Korea) & 39 & $(36.4 \%)$ & 68 & $(63.6 \%)$ & 107 & 10 \\
\hline \multicolumn{7}{|c|}{$\begin{array}{l}\text { In order to interpret these data it is worth mentioning that different reagents were used in all studies to identify serologically D- } \\
\text { samples. } \\
\text { a Homozygous, whole } R H D \text { gene deletion (allele } R H D^{*} 01 N .01 \text { ). } \\
\text { bAll } R H D \text {-positive samples, including hybrid genes, single-nucleotide variations and complex alleles. }\end{array}$} \\
\hline
\end{tabular}

exon copy number variation (fig. 1) [25]. Total deletion of the gene was observed in 118/171 samples (69.0\%), of which 99 and 19 were $\mathrm{C}+(65.6 \%$ of $\mathrm{C}+$ samples $)$ and $\mathrm{E}+(95.0 \%$ of $\mathrm{E}+$ samples $)$, respectively (table 1). In the other 53 samples, hybrid genes were identified and confirmed by RHCE QMPSF in 49 samples at the hemizygous state, and in one sample at the compound heterozygous state (table 1). This latter sample as well as the remaining three hemizygous samples with no variation identified by QMPSF analysis were further analyzed by Sanger sequencing. The compound heterozygous sample was identified to carry a $D-C E(4-9)$ $D$ hybrid allele in trans with the novel $R H D$ (c.701delG) allele (GenBank accession number: KY229721) (fig. 2A). In the other three D-, C+ samples, the previously reported $R H D(\mathrm{~T} 148 \mathrm{R})$ allele (HE861895) [27] as well as two novel variant alleles, including the nonsense $R H D(\mathrm{Y} 243 \mathrm{X})$ and complex $R H D(\mathrm{~T} 148 \mathrm{R}, \mathrm{T} 195 \mathrm{M})$ alleles (KY229722 and KY229723, respectively), were found (fig. 2B-D).

\section{Discussion}

We investigated the genetic bases of $\mathrm{D}$ - phenotype in $\mathrm{D}-, \mathrm{C} / \mathrm{E}+$ donors of Indian origin by standard molecular analysis of the RHD gene. Homozygous deletion of the whole RHD gene, i.e. $R H D^{\star} 01 N$.01, was found to be the most common $D$ - allele (allele frequency $=0.842$ ) in Indians (table 1 ) as typically observed in Europeans. This frequency appears to be intermediate between Caucasians and East Asians (table 2). 
Apart from RHD deletion, two other mutational mechanisms causing D negativity have been identified in the present study: hybrid genes and single-point mutations (table 1; allele frequency = 0.146 and 0.012 , respectively). Three different hybrid genes were deduced from QMPSF analysis (table 1). First a RHD-CE(3-9)-D hybrid allele was identified. On direct sequencing of RHD exon 2, the $c .203 \mathrm{G}>\mathrm{A}$ variation was not present (data not shown), suggesting that this allele is $R H D^{\star} 01 N .03$. On the basis of our data we assume that $R H D-C E(3-8)-D$ is likely to be similar to $R H D^{\star} 01 N .05$, also referred to as RHD-CE(2-7)-D and RHD-CE(3-7)-D (RhesusBase; $w w w . r h e s u s b a s e . i n f o /)$. Indeed investigating the origin of exons 2 and 8, which share common sequences in both RHD and RHCE [28], may yield different results as location of PCR primers in intronic regions varies depending on the original locus, while exonic sequences are the same. To our knowledge this allele has been reported in Caucasians only to date $[7,9,16]$. In 6 individuals, $R H D$-CE(4-9)-D allele was identified (table 1: Ccee, 5 ; ccEe, 1 ). $\mathrm{Li}$ and colleagues [24] reported an apparently similar allele in a single Chinese individual, officially registered as $R H D^{\star} D E L 44$, expressing a DEL phenotype. However in the present study, adsorption-elution studies showed absence of DEL phenotype in these individuals. This observation is somehow intriguing. From a strict molecular point of view, as $R H D^{*} 01 N .07$, a $R H D-C E(4-7)-D$ hybrid allele lacking four $R H D$-specific exons critical for the expression of the $\mathrm{D}$ antigen, results in the expression of a D- phenotype [7]; same phenotype may be expected from RHD-CE(4-9)-D, which even lacks a higher number of $R H D$-specific exons. Additional functional analyses as well as investigation of antigen density will help to conclude definitely.

Contrary to hybrid genes found in almost one-third of samples (i.e. 31.0\%), single-nucleotide variations are rare in $\mathrm{D}-, \mathrm{C} / \mathrm{E}+\mathrm{Indi}-$ ans, as only four individuals each harboring a different allele were found. While genotype-phenotype correlation is obvious in individuals carrying either a nonsense or frameshift variation, the molecular mechanism(s) driving D negativity in the other two missense alleles is (are) still to be determined. Interestingly, these latter alleles share the c.443C $>\mathrm{G}$ variation, which results in the replacement of a threonine amino acid by an arginine residue at position 148 (p.Thr148Arg) of the RhD protein. It is actually the second time this amino acid substitution is reported to be associated to D negativity [27], confirming that this missense variation completely impairs the membrane expression of the $\mathrm{RhD}$ protein.

Overall we report the molecular bases of $\mathrm{D}$ antigen negativity in the $\mathrm{D}-, \mathrm{C} / \mathrm{E}+$ Indian population, which appears to be qualitatively similar to other populations, but with a specific quantitative distribution of $D$-- alleles. On the basis of our data it may be valuable to design a simple molecular test to analyze presence of $R H D$ gene in D- individuals.

\section{Acknowledgment}

This work was supported by the Indo French Center for the Promotion of Advanced Research (IFCPAR/CEFIPRA, project n ${ }^{\circ}$ 5203-1), the National Institute of Immunohematology (NIIH, ICMR), the Etablissement français du sang (EFS) Bretagne and the Institut National de la Santé et de la Recherche Médicale (Inserm), France.

\section{Disclosure Statement}

The authors declare that they have no conflict of interest.

\section{References}

1 Avent ND, Reid ME: The Rh blood group system: a review. Blood 2000;95:375-387.

2 Daniels G: Rh and RHAG blood group systems; in Daniels G (ed): Human Blood Groups. 3rd ed. Oxford, Blackwell Publishing, 2013, pp 182-258.

3 Colin Y, Chérif-Zahar B, Le Van Kim C, Raynal V, Van Huffel V, Cartron JP: Genetic basis of the RhDpositive and RhD-negative blood group polymorphism as determined by Southern analysis. Blood 1991;78: 2747-2752.

4 Okuda H, Kawano M, Iwamoto S, Tanaka M, Seno T, Okubo Y, Kajii E: The RHD gene is highly detectable in RhD-negative Japanese donors. J Clin Invest 1997;100: 373-379.

5 Wagner FF, Flegel WA: RHD gene deletion occurred in the Rhesus box. Blood 2000;95:3662-3668.

6 Singleton BK, Green CA, Avent ND, Martin PG, Smart E, Daka A, Narter-Olaga EG, Hawthorne LM, Daniels G: The presence of an RHD pseudogene containing a 37 base pair duplication and a nonsense mutation in Africans with the Rh D-negative blood group phenotype. Blood 2000;95:12-18

7 Wagner FF, Frohmajer A, Flegel WA: RHD positive haplotypes in D negative Europeans. BMC Genet 2001 2:10.
8 Shao CP, Maas JH, Su YQ, Köhler M, Legler TJ: Molecular background of Rh D-positive, D-negative, $\mathrm{D}_{\mathrm{el}}$ and weak D phenotypes in Chinese. Vox Sang 2002;83: 156-161.

9 Gassner C, Doescher A, Drnovsek TD, Rozman P, Eicher NI, Legler TJ, Lukin S, Garritsen, Kleinrath T, Egger B, Ehling R, Körmöczi GF, Kilga-Nogler S, Schoenitzer D, Petershofen EK: Presence of RHD in serologically D-, C/E+ individuals: a European multicenter study. Transfusion 2005;45:527-538.

10 Kim JY, Kim SY, Kim CA, Yon GS, Park SS: Molecular characterization of D- Korean persons: development of a diagnostic strategy. Transfusion 2005;45:345-352.

11 Qun X, Grootkerk-Tax MG, Maaskant-van Wijk PA, van der Schoot CE: Systemic analysis and zygosity determination of the RHD gene in a D-negative Chinese Han population reveals a novel D-negative RHD gene. Vox Sang 2005;88:35-40.

12 Ye LY, Guo ZH, Li Q, Zhu ZY: Molecular and family analyses revealed two novel $R H D$ alleles in a survey of a Chinese RhD-negative population. Vox Sang 2007; 92:242-246.

13 Flegel WA, von Zabern I, Wagner FF: Six years' experience performing RHD genotyping to confirm D- red blood cell units in Germany for preventing anti-D immunizations. Transfusion 2009;49:465-471.
14 Christiansen M, Sørensen BS, Grunnet N: RHD positive among $\mathrm{C} / \mathrm{E}+$ and $\mathrm{D}-$ blood donors in Denmark. Transfusion 2010;50:1460-1464.

15 Cruz BR, Chiba AK, Moritz E, Bordin JO: RHD alleles in Brazilian blood donors with weak D or D-negative phenotypes. Transfus Med 2012;22:84-89.

16 Orzińska A, Guz K, Polin H, Pelc-Kłopotowska M, Bednarz J, Gieleżyńska A, Śliwa B, Kowalewska M, Pawłowska E, Włodarczyk B, Malaga M, Żmudzin A, Krzemienowska M, Srivastava K, Michalewska B, Gabriel C, Flegel WA, Brojer E: RHD variants in Polish blood donors routinely typed as D-. Transfusion 2013; 53:2945-2953

17 Costa S, Martin F, Chiba A, Langhi Jr D, Chiattone C, Bordin J: RHD alleles and $\mathrm{D}$ antigen density among serologically D- C+ Brazilian blood donors. Transfus Med 2014;24:60-61.

18 Moussa H, Tsochandaridis M, Kacem N, Chakroun T, Abdelkefi S, Gabert J, Levy A, Jemni Yacoub S: RHD positive among $\mathrm{C} / \mathrm{E}+$ and $\mathrm{D}$-negative blood donors in Tunisia. Transfus Clin Biol 2014;21:320-323.

19 Trucco Boggione C, Luján Brajovich ME, Tarragó M, Mattaloni SM, Biondi CS, Muñiz-Díaz E, Nogués N, Cotorruelo CM: Molecular structures identified in serologically D- samples of an admixed population. Transfusion 2014;54:2456-2462. 
20 Ogasawara K, Suzuki Y, Sasaki K, Osabe T, Isa K, Tsuneyama H, Uchikawa M, Satake M, Tadokoro K Molecular basis for D- Japanese: identification of novel DEL and D- alleles. Vox Sang 2015;109:359-365.

21 Kumar H, Mishra DK, Sarkar RS, Jaiprakash M: Diffi culties in immunohaematology: the weak D antigen. Med J Armed Forces India 2005;61:348-350.

22 Kulkarni SS, Gupte SC, Vasantha K, Mohanty D, Ghosh K: Varied distribution of RhD epitopes in the Indian population. Natl Med J India 2007;20:169-171.

23 Thakral B, Saluja K, Sharma RR, Marwaha N: Phenotype frequencies of blood group systems (Rh, Kell, Kidd, Duffy, MNS, P, Lewis, and Lutheran) in north Indian blood donors. Transfus Apher Sci 2010;43:17-22.
4 Li Q, Hou L, Guo ZH, Ye LY, Yue DQ, Zhu ZY: Molecular basis of the RHD gene in blood donors with DEL phenotypes in Shanghai. Vox Sang 2009;97:139146.

25 Fichou Y, Le Maréchal C, Bryckaert L, Dupont I, Jamet D, Chen JM, Férec C: A convenient qualitative and quantitative method to investigate RHD-RHCE hybrid genes. Transfusion 2013;53:2974-2982.

26 Fichou Y, Le Maréchal C, Jamet D, Bryckaert L, Ka C, Audrézet MP, Le Gac G, Dupont I, Chen JM, Férec C: Establishment of a medium-throughput approach for the genotyping of $R H D$ variants and report of nine novel rare alleles. Transfusion 2013;53:1821-1828.
27 Stegmann TC, Veldhuisen B, Bijman R, Thurik FF, Bossers B, Cheroutre G, Jonkers R, Ligthart P, de Haas M, Haer-Wigman L, van der Schoot CE: Frequency and characterization of known and novel RHD variant alleles in 37782 Dutch D-negative pregnant women. Br J Haematol 2016;173:469-479.

8 Mouro-Chanteloup I, Colin Y, Chérif-Zahar B, Cartron JP, Le Van Kim C: Molecular genetic basis of the human Rhesus blood group system. Nat Genet 1993;5: 62-65. 